\title{
Correction to: Potential revenue and breakeven of energy storage systems in PJM energy markets
}

\author{
Maurício B. C. Salles ${ }^{1}$ (D) $\cdot$ Taina N. Gadotti $^{1} \cdot$ Michael J. Aziz ${ }^{2} \cdot$ William W. Hogan ${ }^{3}$
}

Published online: 23 January 2019

(C) Springer-Verlag GmbH Germany, part of Springer Nature 2019

\section{Correction to: Environmental Science and Pollution Research https://doi.org/10.1007/s11356-018-3395-y}

The original publication of this paper contains a mistake.

Correct images for Figures 11, 12 and 13 are shown in this paper.

The online version of the original article can be found at https://doi.org/ 10.1007/s11356-018-3395-y

Maurício B. C. Salles

mausalles@usp.br

Taina N. Gadotti

taina.gadotti@usp.br

Michael J. Aziz

maziz@ harvard.edu

William W. Hogan

william_hogan@harvard.edu

1 Laboratory of Advanced Electric Grids - LGrid, Polytechnic School,

University of São Paulo - USP, São Paulo, Brazil

2 John A. Paulson School of Engineering and Applied Sciences, Harvard University, Cambridge, USA

3 John F. Kennedy School of Government, Harvard University, Cambridge, USA 
Fig. 11 Distribution of breakeven overnight installed cost for the average revenue vs. energy capacity (1 MW, 1-14MWh) of the selected nodes in the PJM RTMarket using DAM as a forecast. Assumed round trip efficiency is $70 \%$ and project lifetime is 20 years for 1 MWof rated power

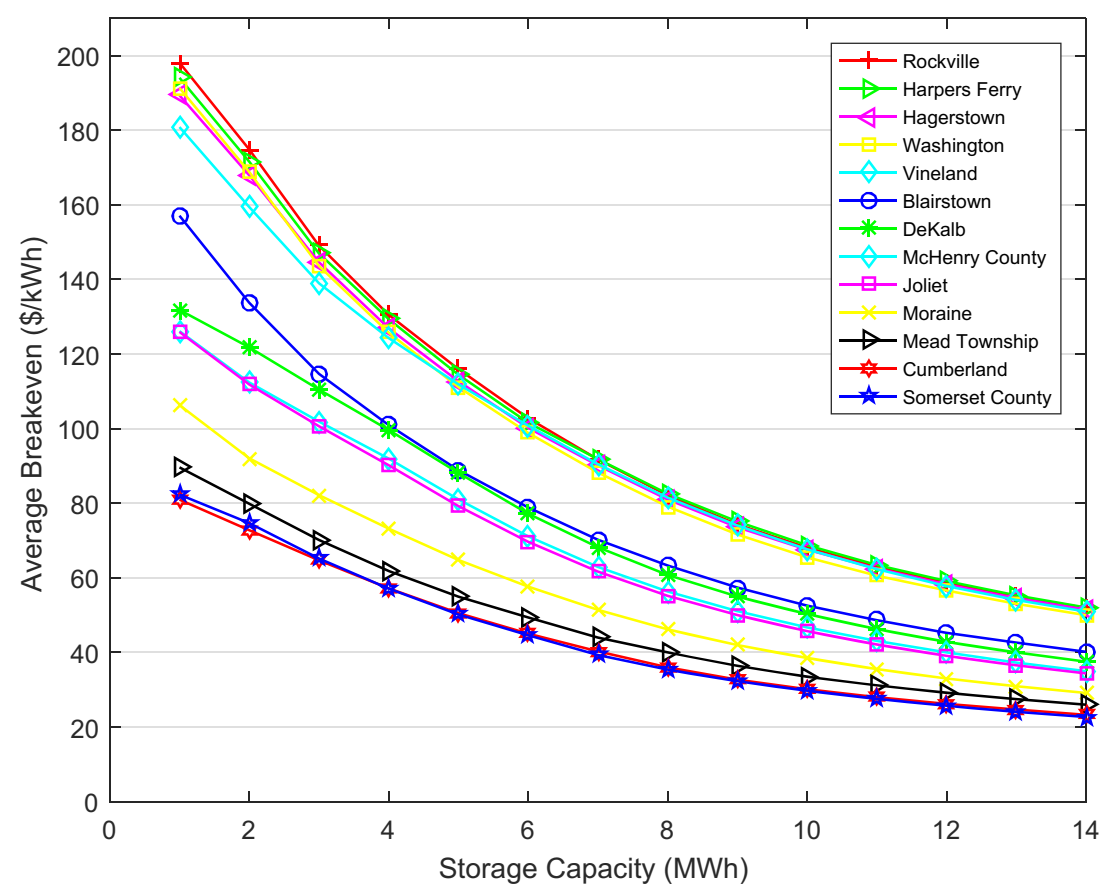

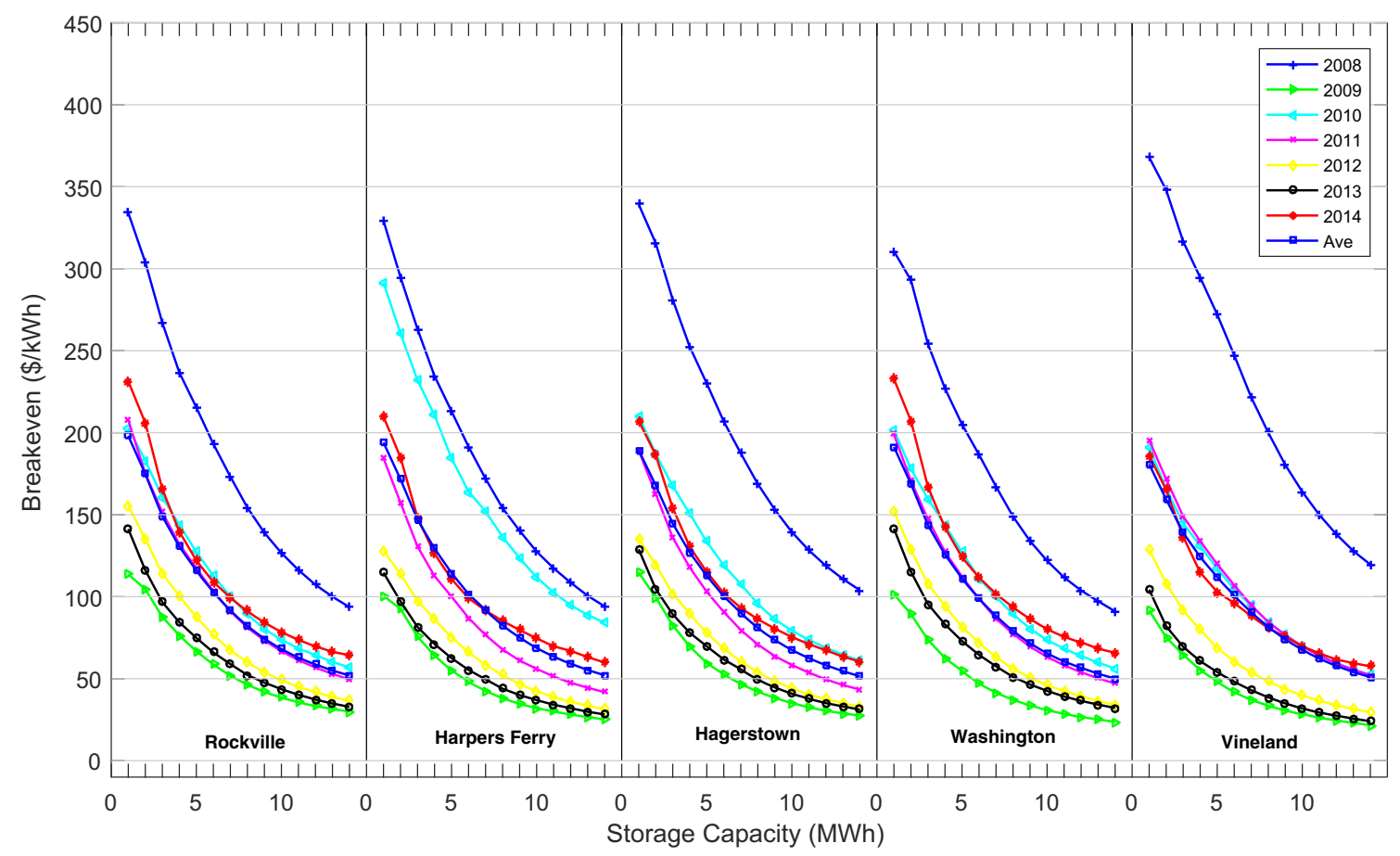

Fig. 12 Distribution of breakeven overnight installed cost for the group of high potential revenue nodes in the PJM RT-Market using the DAM settlement prices as forecast, for a 1 MWof rated power ESS vs. energy capacity (1-14 MWh) for each year between 2008 and 2014. Assumed round trip efficiency is $70 \%$ and project lifetime is 20 years 


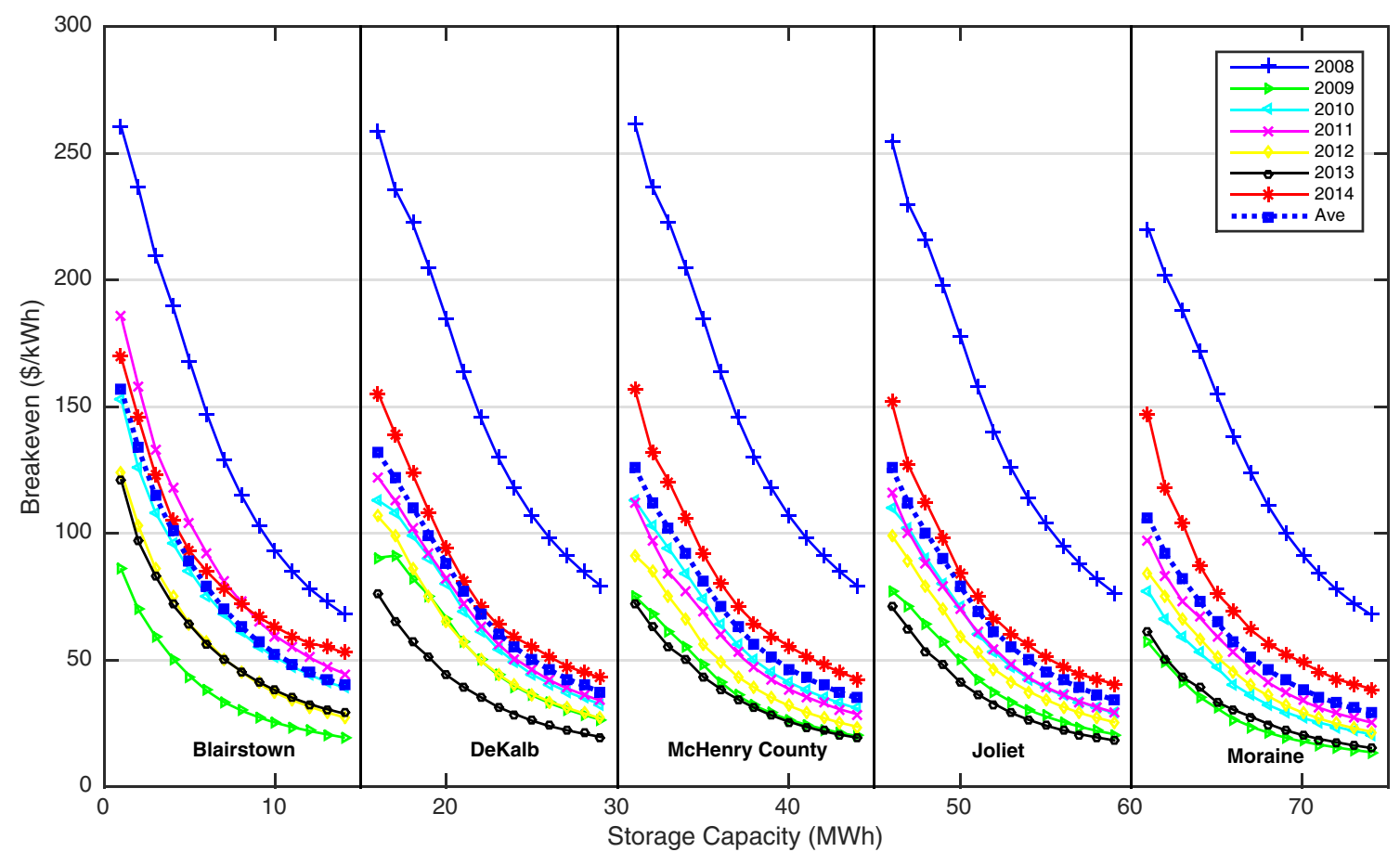

Fig. 13 Distribution of breakeven overnight installed cost for the group of intermediate potential revenue nodes in the PJM RTMarket using theDAMsettlement prices as forecast, for a 1 MWof rated power ESS vs. energy capacity (1-14 MWh) for each year between 2008 and 2014. Assumed round trip efficiency is $70 \%$ and project lifetime is 20 years

The original article has been corrected.

Publisher's Note Springer Nature remains neutral with regard to jurisdictional claims in published maps and institutional affiliations. 